\title{
Comparative study: TQ and Lean Production ownership models in health services
}

\author{
Natalia Yuri Eiro ${ }^{1}$ \\ Alvair Silveira Torres-Junior ${ }^{2}$
}

Objective: compare the application of Total Quality (TQ) models used in processes of a health service, cases of lean healthcare and literature from another institution that has also applied this model. Method: this is a qualitative research that was conducted through a descriptive case study. Results: through critical analysis of the institutions studied it was possible to make a comparison between the traditional quality approach checked in one case and the theoretical and practice lean production approach used in another case and the specifications are described below. Conclusion: the research identified that the lean model was better suited for people that work systemically and generate the flow. It also pointed towards some potential challenges in the introduction and implementation of lean methods in health.

Descriptors: Quality Management; Health Services Administration; Health Management; Quality Improvement.

\footnotetext{
1 Doctoral student, Faculdade de Economia, Administração e Contabilidade, Universidade de São Paulo, São Paulo, SP, Brazil.

${ }^{2}$ PhD, Professor, Faculdade de Economia, Administração e Contabilidade, Universidade de São Paulo, São Paulo, SP, Brazil.
}

Corresponding Author: Natalia Yuri Eiro

Rua Manuel Figueiredo Landin, 50 Bairro: Campo Grande

CEP: 04693-130, São Paulo, SP, Brasi

E-mail: natalia_eiro@yahoo.com
Copyright () 2015 Revista Latino-Americana de Enfermagem This is an Open Access article distributed under the terms of the Creative Commons Attribution Non-Commercial License (CC BY-NC).

This license lets others distribute, remix, tweak, and build upon your work non-commercially, and although their new works must also acknowledge you and be non-commercial, they don't have to license their derivative works on the same terms. 


\section{Introduction}

The health institutions in Brazil wish to achieve efficient identification, control and management of costs by promoting a better quality of service. The pursuit of quality care in the health services is no longer an isolated attitude, but also a technical and social imperative.

Yet, the theme is applicable within nursing purposes, because such professionals can be found among the operational field from an institution due to long working hours, interacting with several agents and resources coming from miscellaneous processes. Whether there is a professional who has a general overview of what happens in a hospital, a clinic environment, or from a specific locus, this should be the nurse. The nurse is supposed to interact and handle the dynamics of such a place and deal with all the different types of customers that attend that establishment.

The dynamics of the labor process is very different from several types of health services; however, to meet the needs, customer expectations and achievement of excellence, it is essential that managers of organizations build and practice a policy of quality linked to continuous monitoring which enables products and services with greater uniformity, decreases non-compliance, achieves lower costs, avoids waste and repetition of work and finally embraces quality ${ }^{(1)}$.

The awakening of the topic of health care quality is due to multiple reasons that can be highlighted by the increase in demand for health care, increasing costs for the maintenance of services and limited available resources $^{(2)}$.

These desires for quality and productivity improvements are caused by developments that have happened in the industry since the dawn of business administration. More recently with research on the Japanese model, the studies over this area have been intensified and innovated. This study aims to compare the application of the TQ models still used in critical processes of the health service, cases of lean healthcare and literature from another institution that has applied this model.

Several observations of such a study arise from an analogy with the continuous improvement processes that are already performed in the manufacturing and service sectors, and once measured, it is possible to provide the outcomes for the patient and the health care institution, which are also a premise that must be kept constant throughout this study.

\section{Model of Total Quality Management (TQM)}

The concept of quality is rooted according to some theorists and this term had its beginning in the twentieth century with the development and manufacturing industry organizations for large-scale production and where there have been huge changes in work processes and increased productivity, the intensive auxiliary machines for mass production and strong concern with the uniformity of the product led to inspection activities to maintain the standard model(3).

From this perspective, companies began to use quality indicators and implement programs that incorporate rigorous evaluation parameters of organizational performance and assign, according to the classification of the assessed organization, the possibility of obtaining greater resources and market expansion. TQM has been implemented in health services directly as one model of management or indirectly as support for the health accreditation process ${ }^{(3-4)}$.

\section{Lean Production Model (lean production)}

Lean production is defined as a strategy that seeks for a better way to organize and manage the relationships of a company with customers, supply chains, product development and production operations, whereby it is possible to do more with less waste (less equipment, less human effort, less time), through the identification of improved primary value flows and support through the involvement of qualified, motivated and initiative personnel(5).

There are five principles that describe lean production $^{(5)}$ :

- Value: specify the value desired by the customer;

- Value chain: set of all specific actions required in order to deliver a product to the customer and the companies must check the whole process;

- Flow: for a process to have its own flow, a change of mind is required concerning department division, as the most feasible solution;

- Production drawn: concerned with cost reduction efforts, and reductions in time and space used. The flow effect can be felt in the reduction of product design time, processing and inventory and;

- Perfection: all chain members need to be aware of the process as a whole, allowing them to discuss and 
continually seek more effective efforts in order to create value.

For lean production to achieve the goals, it is necessary to apply some tools that will assist in achieving the results. The tools are instruments used to implement a lean production system, operationalizing its principles. They are: value stream mapping (VSM), the identification of all the specific activities occurring along the value stream for the product process $^{(6)}$; just in time (JIT) is a programming system to pull together the flow of the production and inventory control system. To coordinate this stream we use the Kanban method to visually monitor the processes; gemba walks denote the action of going to see the actual process, understand the work, ask questions and learn; standardized work, the analyst must seek the fulfillment of Kaizen to identify the causes and promote continuous improvement ${ }^{(7)}$; visual management: visual display of all the tools, activities and indicators of the production system, so that the current situation can be quickly understood by all involved; $A 3$, is a tool that makes use of an A3 paper sheet to describe, in accordance with standard patterns, each problem or challenge that a company presents, and it is also necessary to detail how it will be addressed with the respective analyses, corrective actions and action plans ${ }^{(5)}$.

There are other tools described in the literature. However, those listed in this article are those that are most frequently mentioned in the application of lean in health literature, known by the movement lean healthcare ${ }^{(8)}$.

In order to gather the best results it is important to eliminate waste. Inside the manufacturing context, such waste was split into seven categories ${ }^{(7)}$ : overproduction, standby time, transportation, excess processing, stock, unnecessary movement, and default.

\section{Lean healthcare model}

Lean healthcare is a philosophy based on the concepts of lean production and it's applied to health that improves the way health services are organized and

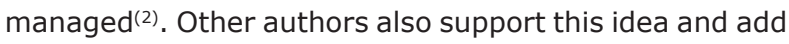
that lean thinking in healthcare should be seen as an operational and integrated approach (processes), sociotechnical (team behavior and technology perspectives) of a value system, whose main objectives are to maximize patient value and eliminate waste through the creation of cumulative knowledge ${ }^{(9)}$.

In the lean healthcare model, the principles are grounded in patient care and they are focused on patients instead of the hospital or staff; identify value for the patient and eliminate waste and minimize treatment times. Nowadays in the healthcare environment, the nurse's day is often overburdened with waste that forms a barrier between the nurse and the nurse's ability to care for patients, this distances them from the bedside and prevents them from caring for their patients. For nurses to be able to establish a caring relationship they must be present with their patients ${ }^{(10)}$.

Some cases studied in the literature reveal how institutions, with the implementation of the lean healthcare model, can provide patient focused care with better therapeutic and interventional outcomes, operational management improvements, increased customer and staff satisfaction and also with less waste and costs. These services have found that the best results would be achieved via a collaborative treatment, i.e., contemporary management models propose participatory management with a greater involvement of employees in the decision making process, sharing responsibility and sharing power ${ }^{(10-11)}$.

\section{Method}

Methodologically, this paper is a discussion arising from the research field in two health services that authorized the collection of data and analysis of literature, resulting in a survey of a number of relevant points for the subsequent conduct of the case studies in this research, which compared the management models from these two health institutions observing their critical processes $^{(12-13)}$.

The case study took place between May and June 2012 at a private company of a huge medical diagnostic service that meets classes $A, B$ and $C$ (case A) distributed in various regions of the country and in June 2013 in a medium-sized private hospital located in São Paulo, specializing in oncology, which serves about 200 patients a day (case $B$ ), private and insured patients. In case $B$, the lean method had already been implemented.

The observation protocol and data collection services complied with the following stages: observation of care flow between sectors, participant observation from researchers ${ }^{(14)}$, interviews with managers ${ }^{(12)}$, reviews of perceived waste and exposure by operational staff and managers and questions that encompassed five dimensions for the comparison of management models and dismemberment of three basic elements of any given management model: purpose, structure and resources. The common socio-technical system model in 
the theoretical bases used in $\mathrm{TQ}^{(15)}$ and lean ${ }^{(5)}$, was the drive to dismember the basic elements of management in a row dimensions of analysis through interviews and observations. The purpose is dismembered in the characterization of scope, main focus and model structure, and is divided into their social and technical approaches and their resources for the tools (Figure 1). For data analysis we used comparisons between case $A$, case $B$ and other cases that had been described in the literature(16).

\begin{tabular}{|c|c|c|c|}
\hline & Case A & Case B & Literature - Lean Healthcare Cases \\
\hline Scope & $\begin{array}{l}\text { Analysis of the indicators that were } \\
\text { off target and attempt to control the } \\
\text { results in a formal way (scorecard } \\
\text { and monthly meetings with } \\
\text { management) }\end{array}$ & $\begin{array}{l}\text { Operational team participates in MFV; } \\
\text { proposes a map of the ideal process } \\
\text { and a plan of action. The planning and } \\
\text { implementation of each step depends on } \\
\text { the board }\end{array}$ & $\begin{array}{l}\text { Implementation of improvements through } \\
\text { knowledge of the entire process and } \\
\text { identifying the causes of problems by MFV } \\
\text { by all process participants. }\end{array}$ \\
\hline Focus & $\begin{array}{l}\text { Intervention abnormalities manager } \\
\text { of the sub processes; operating } \\
\text { sectors only serve customers who } \\
\text { are within standard care. }\end{array}$ & $\begin{array}{l}\text { Many professionals (managers, operations, } \\
\text { strategists, others) are scaled to map the } \\
\text { processes and apply the FMEA to predict } \\
\text { the risks of each step of the flow. }\end{array}$ & $\begin{array}{l}\text { Systemic view of all processes with the } \\
\text { involvement of all areas and professionals }\end{array}$ \\
\hline Social approach & $\begin{array}{l}\text { Bureaucratic and punctual; with } \\
\text { more centralized decisions from the } \\
\text { coordinator of the Unit. }\end{array}$ & $\begin{array}{l}\text { All the team assist in the definition of MFV; } \\
\text { apply previous knowledge, interaction. If } \\
\text { necessary open security alerts and use the } \\
\text { A3 tool. }\end{array}$ & $\begin{array}{l}\text { Procedural by mapping flows, involving } \\
\text { managers, leaders and operational staff }\end{array}$ \\
\hline $\begin{array}{l}\text { Technical } \\
\text { approach }\end{array}$ & $\begin{array}{l}\text { The coordinators seek to find the } \\
\text { root cause and are responsible for } \\
\text { irregularities and proposing specific } \\
\text { corrective actions }\end{array}$ & $\begin{array}{l}\text { With MFV, it is possible to identify the } \\
\text { opportunity to apply other tools whether } \\
\text { created by the lean movement or } \\
\text { originated by the prior knowledge of the } \\
\text { group (eg FMEA) and propose process } \\
\text { improvements. }\end{array}$ & $\begin{array}{l}\text { New work culture which aims at eliminating } \\
\text { waste within the processes by identifying } \\
\text { the causes with analysis of the entire flow }\end{array}$ \\
\hline Tools & Flowcharts, PDCA, Pareto Diagram & $\begin{array}{l}\text { 5S, A3, FMEA, Mapping Flow, PDCA, } \\
\text { Kaizens }\end{array}$ & Quality tools + specific job analysis \\
\hline
\end{tabular}

Figure 1 - Comparison of cases according to the elements of Management Models. São Paulo, SP, Brazil, 2013

The visits followed the following research protocol: 1) meeting with responsible service manager for clarification, 2) semi structured interviews with the manager addressing the five dimensions noted above 3 ) observation of the service to search for evidence and other manifestations of what was covered in the interview 4 ) unstructured interview with the nursing professional responsible for the observed procedures regarding the problems that they had experienced and the response procedures and, 5) Return to the manager interviewed for clarification of what was observed.

\section{Results}

Case A - sector in the area of Diagnostic Medicine responsible for conducting clinical tests and imaging whose objective is to support the diagnosis in the detection or exclusion of diseases. A mapping flow service was applied to a customer who visits a Unit for biological material collection and where three different critical processes were selected. To collect the data, in case A, after analyzing the quality indicators, the processes were chosen according to the worst results in order to be mapped.
Procedure $1 \mathrm{~A}$ - The attendance is considered a focus area of the service sector, because it is the place where the interaction with the customer happens, as well as being considered as an operational area. The first selected process was the opening record, as soon as the customer arrives at the unit, he takes a password and waits until his name is announced. This period is essential for the next steps because the delay in the waiting room can generate stress and dissatisfaction on the customer's side. The customer's next step, after waiting in the reception area, is to open his record. In this stage the receptionist will register all exams according to health plan coverage or private payment, check the personal data and release an attendance record so that the nursing staff are able to prepare the kit tubes while the client waits for the procedure to be announced. The surveyed information revealed that the receptionists had many doubts and committed errors while the opening record was created, they did not include examinations or improperly registered tests. Another highlighted problem was that the receptionists depended too much on the coordinator to have a dialog with customers at any given stage of the proceedings and the standard of care was diverted. An example is when the client forgot the identification or the prescription or when there was 
no prior authorization for the procedure to be performed or when there was too much waiting time and the clients complained about something. This finding is confirmed by the results achieved from the service complaint index where the highest incidences of complaints are related to waiting time ( $28 \%$ of total complaints) and the second was errors in the opening record (15\% of total complaints). In 2012, with the use of the TQM model, each manager performed the cause analysis of the final results by proposing a specific corrective action in each unit and subsequently spread the results achieved from such work. In this process, in order to decrease errors in the opening record, an employee was chosen to make a second check of the records prior to data collection.

Procedure 2A - The second analyzed case was the collection of biological material. This procedure is performed by the nursing staff and whether or not the whole care protocol is strictly followed, some recollections might be generated (recalls for the procedure). The collection of biological material is the first step for all analyses performed in the clinical laboratory. It depends on all of the following steps; due to this reason, without a correct collection procedure, it is impossible to get accurate results. Although there are reviews and discussions on the ideal setting for the collection of venous blood, thus, there are observed variations in the venipuncture procedure between different laboratories and different professionals.

During the collection of biological material, one of the indicators most commonly mentioned in the literature on clinical laboratory management refers to the recollection index, the grounds are given as ${ }^{(17)}$ : errors in opening registration (misidentification of patient or medic and errors identified in the examination records); requested samples not collected by nurses, eg., when the label is not properly printed or the printer fails; mistakes in the collection (collecting the wrong tube, hemolysis, clotted samples and inadequate ratio of blood/anticoagulant, improper packaging), problems in the transportation of samples.

The recalls to confirm results or inappropriate material happen when it is required to repeat the tests and the blood volume is not sufficient. The cases related with record opening errors, collections made in the wrong tube/bottle, samples not collected and improper packaging can only be reversed without the customer's realization if the employee who caused the damage or if another employee in the same generator sector notices the problem before the material arrives in the technical area. In the health service in general, with these errors in mind, a record crosscheck is performed before the nursing staff begin to execute the procedure and there is also a crosscheck for material packaging and safety in the shipping case that is forwarded to technical department.

The misplacement/loss of material can occur when blood is collected (at the client's home or at the clinics) in transit between the collection location and the technical area.

In this process the main indicator analyzed is the recollection index, at the institution studied the data survey showed that the status of this indicator was greater than the recommended target ( $49 \%$ above). The coordinators individually evaluated the causes of client recall and whether or not it is out of the range, they can also propose a remedial action in the unit as in the previous case. And in a monthly meeting it is exposed to the whole company and then a comparison among the various units is made.

Case B - sector in the midsized hospital department, specialized in the diagnosis and treatment of cancer in the state of São Paulo. This institution is certified by national and international accreditations. This hospital has been using the lean healthcare model since 2008, when the first mapping projects were executed after the initial decision by senior management ${ }^{(18)}$. The service used some quality tools for the process analysis such as FMEA, due to certification requirements in order to meet legal norms. The lean thinking came after ONA process (level 3 of excellence) certification, when they identified a large amount of labor repetition and reprocessing.

The selected files were displayed and analyzed during interviews and then visits to industries and offices were also performed. Before the introduction of lean healthcare, company B had a quality system modeled on the TQ system used along with a formal accreditation system.

Case $1 \mathrm{~B}$ - In this case, the start of the lean healthcare model happened by indicating the managers and directors of the processes that could generate a greater impact on patient safety indicators and for those who were in critical conditions this meant comparing the institutions in the same field with the worst results. One of the processes studied in the hospital was the pre-chemotherapy procedure that happens outside the pharmacy and that depends on the front desk's work of correctly registering the patient, on the nursing triage and on the doctor prescribing the medication treatment ${ }^{(18)}$.

The stages of chemotherapy treatment are: the patient initiates the procedures in reception where the 
attendance information is collected; this will be followed by the blood pressure and weight measurement and along with the basic informed data, the patient goes to medical care in which he will be evaluated and a prescription will be generated with the guidelines for the medication. Then, the pharmacy manipulates the prescription, the nurse evaluates the patient before chemotherapy is started and the chemotherapy medication is managed. At the end of the treatment, the patient is released and is able to leave the hospital (18).

One of the most critical phases of the process is the prescription for the treatment of this pathology and at this hospital there were avoidable failures during the prescription stage. After this critical situation, the board assembled a study group that had a weekly meeting to assess all risks during this process by mapping the flow complemented by the analysis of adverse events through the FMEA quality tool and the A3 lean tool. The interviews and observations reveal that this association of lean tools (MFV) along with a traditional quality
(FMEA), allowed the management board to focus on the quality loss as a waste and to raise awareness to their causes. The FMEA review, when practiced in an isolated way, is based on the fact that its accomplishment depends on experts who may raise the issues of potential failures into the process, however, quite far from the real flow, with the analysis taking place in meeting rooms ${ }^{(18)}$

In the practiced lean, MFV highlights that is important to visit the workplace and make questions regarding the possible faults, through direct observation of potential faults with the interaction between specialists and operational workers. It is this interaction with the phenomenon which ensures the effectiveness of the FMEA technique which can create more specific questions that may fail based on the observations by MFV. In Figure 2, measurements are observed for controlling and detecting the faults arising from the observation of the flow improvement group and that were formalized in the FMEA structure used by the TQ Model(18).

\begin{tabular}{|l|l|l|}
\hline \multicolumn{1}{|c|}{ Failure type } & \multicolumn{1}{|c|}{ Failure effect } & \multicolumn{1}{c|}{ Measure to control and detect the fail } \\
\hline Error prescription & Wrong drug administration & Different label in accordance with the drug and standardized checks by nurses \\
\cline { 2 - 3 } & Wrong dose administration & Double confirmation of the weight screening \\
\cline { 2 - 3 } & $\begin{array}{l}\text { Prescription deletion due to } \\
\text { drench adjustment }\end{array}$ & Any drench correction would be performed by a doctor through the proper form \\
\hline Wrong name & Incorrect medication & $\begin{array}{l}\text { Drug and all remaining medical records identification would be performed through } \\
\text { standardized labels }\end{array}$ \\
\hline Wrong weight & Incorrect drench & Block more than one prescription/day and for periods > 60 days \\
\hline
\end{tabular}

Figure 2 - Description of faults during the prescription stage, effects and preventive measures. São Paulo, SP, Brazil, 2013

Procedure 2B - A second process also essential in patient care is the handling and preparation of medicines by the pharmacy. For this procedure to be performed, safety flow mapping was widespread within the sector. The pharmacy receives the prescription and confirms the patient's name, birth date and mother's name. This last check is performed as a security measure, avoiding protocol exchanges. After the nurse handles medications and numbers them according to the administration sequence (pre-chemotherapy and chemotherapy), the professional still packs medications using Kanban and puts it in the box with a visual identification (colored) to prevent patient exchange by the nurses ${ }^{(18)}$.

The label exchange and batch and bottle errors were solved with the individual handling of each prescription and the batch is double checked by two people. Through the tools enforcement (MFV supporting the FMEA analysis) which was responsible for evaluating the root causes of such deviations, the occurrence probability and its effects were calculated, turning the figures into a quantified risk value. It was possible to draw a future landscape with a $30 \%$ reduction of these risks when considering MFV interventions. In this study, the FMEA technique was used in reference to the TQ model and hospital accreditation program and once again was present in Case $1 \mathrm{~B}$ and was centralized in the survey of potential risk of the participation of the operational group ${ }^{(18)}$.

Therefore, the risks identified in an FMEA analysis of this nature would be configured in a list based on experts' experiences and not the experience of the concrete phenomenon. It was found that the decision to change any pharmaceutical process was conducted with participation in decisions by all staff involved, this enhanced the elimination of waste, poor quality and also the risk reduction. Regarding the value creation in the chemotherapy infusion process, it was possible to identify MFV opportunities in order to eliminate 70 
min in the daily workload of pharmacists and to increase the patient care time by nurses by 9 minutes. This was possible because waste was observed in unnecessary staff movements and non-continuous procedures by professionals requiring a very detailed knowledge and by task transfers between the most time-consuming functions which did not provide any real customer benefits $^{(18)}$.

\section{Discussion}

All these processes are considered critical, they can directly affect the quality of customer dissatisfaction resulted regarding the perceived service and especially the safety of the care. They're considered by the management board as processes that impact on customer perception. Service processes A and B were analyzed from the perspective of the waste( ${ }^{(8)}$ identified in the processes and five dimensions were elected for management model comparisons (Figure 1).

Scope - Regarding service $A$, in the perspective of total quality, the indicator analysis is formally held by the coordination department and managers without operational workers participation. This finding was noted during the coordination meetings. In the current management model of service $A$, the cases selected that are considered quality indicators, are published monthly in the second half of the following month and the analysis and intervention is centered on the coordination of units according to the target that has been pre-established by the institution.

In service $B$, managers emphasized that the initiation of the lean production organization model was due to orders that came from senior management and that nowadays, after awareness and team training, is possible to involve everyone in MFV, analysis and process improvement. It is known that changing the approach of analysis of the indicators is not a simple task and that the results of this study highlight this result(8). However, lean healthcare emphasizes the engagement from performer strategies in order to achieve this behavioral change. Whereas, in the analyzed case, such efforts could not be stated due to the company's methodology, granting managers' observations through closed door meetings and centralizing all results reviews.

However, this aspect conflicts with the role attributed to strong leadership, combined with the centralizing and authoritarian style (top-down) implementation of the model(8). This result is the conclusion of it not having been possible at this moment for the practical application of the participation from all staff in the diagnosis and analysis of problems.

Focus - In Case A, interaction within the system is not considered and the processes are improved independently, since each coordinator proposed corrective action for the results that were rated below the indicator targets and if a given unit had exceeded the expected results, this was shared for the whole group to be aware of. There is a systemic process view inside this implemented model within the company, however it still widespread among the departments (SIPOC). It was observed in case $A$, that only the processes and attendances that generate problems are granted, by means of root causes acknowledgment and acknowledgement by those responsible.

On the other hand, in service $B$, there is a systemic view of all the flow processes with the involvement of all departments and professionals involved, in the application of VSM and in the early checks where there is waste in the process of aggregation and nonaggregation of value through the use of specific tools.

Social Approach - In service A, following the TQ management model, the idea that this is still a bureaucratic model because decisions are still centralized in the experts was corroborated. The engagement coming from other departments involved (operation) is limited to the boundaries of data/information collection. In case $B$, it was possible to observe an interaction between all areas, however, some tools were utilized that are not specific to the lean production model (FMEA).

Overall, the data found by observing the application of the TQ model contrasts with what is stated in the approach of the lean model in management practices, in which there is involvement of all people that took part in the identification and resolution of problems ${ }^{(8)}$. Thereby, they are considered as procedural actions through mapping flows, applied by managers, leadership and group work operations for continuous improvement, the so called Kaizen. In TQ cases the participation of nursing personnel was reduced to the role of integrating a group analysis of the indicators and to assist in resolving technical problems. Its systemic and integrated training was underutilized due to specific action mechanisms created in bureaucratic plans. In the lean approach the role of the nurse was valued to the extent that the collection and continual observations of date are fundamental in the discussion groups held at the service location. In addition to the indicators, qualitative observations are recognized as valuable information to find the causes and their improvements. 
Technical Approach - Authors criticize TQ management stating that it did not work and that this model has the purpose of creating an internal and parallel bureaucracy focusing on the image and results and not on facts. Besides, it is also said there is a focus on internal processes (known and visible), instead of the most critical ones ${ }^{(15)}$. These points were displayed in the case whereby the leaders want to find the source of problems and their reasons (mistakes in opening record, delay in treatment, recollection) and propose a specific corrective action for them. It can also be noticed when searching for root cause recognition and deciding upon the responses for shortcomings inside value added activities. In another sense, lean production expands the identification of root causes regarding the anomalies in quality processes allied to the removal of wasteful stages within the processes of aggregation and discovering processes that do not add value.

Tools - In the TQ model, quality tools are used, which are techniques that are used to define, measure, analyze and propose systematized solutions for the problems that affect the process' performance. Lean production, beyond the quality tools, makes use of analytical job specific methods such as, mapping, timing, spaghetti graphics and default worksheets. By establishing such tools, the strategies embrace a more continuous improvement feature, whose goal is set to generate value for the customer, increase operational efficiency and, hence, improve the service quality.

\section{Conclusions}

It was found that the system design has not evolved in $T Q$, due to an empirically detected feature witch is denominated as bureaucratic appropriation. The research identified that the lean model is best suited for people who work systemically and generate the work flow, leading to increased adherence and more accordance with what theory prescribes, moving towards an interaction model of staff flow, in solving problems and seeking continuous improvement (case B). On the other hand, TQ model appropriation was more widespread in the management area and the establishment occurred more through the fulfillment of bureaucratic procedures, which were continuously audited and required more stable control. In the literature review, although TQ also discusses the need for employee's embracement of the concept, the fact is that in the perceived cases, this has not been noticed, mainly because of the tools available they lack funds for the wages for that this kind of behavior needs. In the lean model, the MFV tool, which mandatorily prescribes interaction in gemba walk, is able to fit in with such a factor.

Empirically the observation of the phenomenon of diverse ownership of each model by organizations is a fact that we observed in the collected data. On the other hand, context observations and enterprise history from their agents point of view, allow us to speculate that the difference in the appropriation form is due to the QM focus and procedures certification that suggests a very strong emphasis towards bureaucracy, whereas in the lean model, there is a more centralized observation and a phenomenon participation that finds no echo or correspondence in the tradition of bureaucracy allowed by the companies, hence, creating the relative changes in the journey, quality is pursued, with evidence. Clearly this finding in the two cases and in the literature requires confirmation through quantitative research that would have to collect the degree to which companies that adopt TQ or similar, in fact, do not exceed the boundaries from experts meeting with their own tools, leaving the operational staff the secondary task of collecting data driven by analytical tools, whereas in the lean practices, the frequency with which the focus is managed should be crosschecked in order to analyze the phenomenon in place and to monitor its overall discussion, from such a great point of view, without any meanings or interpretations assigned to it, so that afterwards they can represent them through traditional tools. This would be advice from academic order. On the other hand, a practical recommendation which arises from the cases is about the care the health manager should pay attention to, in order to implement the model that will take a more systemic and real or bureaucratic and cropped form of appropriation. The responsibility of nursing professionals with the application of TQ was shifted partially to bureaucratic work records and discussions at meetings, which in principle should be to improve the system, but created more demand for records and notes which caused a loss of focus on problems. On the other hand, the lean model preserves the focus on the patient through the careful observation of the constant flow of procedures by nursing staff, working as a continuous improvement instrument. Thus, the amount of bureaucratic dysfunction observed was zero. Before recommending lean instead of $\mathrm{TQ}$, as a more complete method - in spite of our reading is that there is a lack of TQ emphasis in more continuous flow observations, this makes it less systemic than the lean model - the truth is, that in general, the health manager should take 
responsibility to continuously care for the observation of the workflow.

\section{References}

1. Pedroso MC, Malik AM. As Quatro Dimensões Competitivas da Saúde. Harvard Business

Rev. 2011;89:59-67.

2. Fonseca PC, Ferreira MAM. Investigação dos níveis de eficiência na utilização de recursos no setor de saúde: uma análise das microrregiões de Minas Gerais. Saúde Soc. $2009 ; 18(2)$ : 199-213.

3. Gurgel GD Junior, Vieira MMF. Qualidade total e administração hospitalar: explorando disjunções conceituais. Ci Saúde Coletiva. 2002;7(2):325-34.

4. Manzo BF, Ribeiro HCTC, Brito MJM, Alves M. Nursing in the hospital accreditation process: practice and implications in the work quotidian. Rev. Latino-Am. Enfermagem. 2012;20(1):151-8.

5. Womack JP, Jones DT. Beyond Toyota: how to root out waste and pursue perfection. Harvard Business Rev. $1996 ; 74(5): 140$.

6. Rother M, Shook J. Learning to see: value stream mapping to add value and eliminate MUDA. Cambridge (MA): Lean Enterprise Institute; 2003.

7. Ohno T. Toyota production system: beyond largescale production. Portland: Productivity; 1988.

8. Shah R, Ward PT. Lean manufacturing: context, practice bundles, and performance. J Operations Manage. 2003;21:129-49.

9. Joosten T, Bongers I, Janssen R. Application of lean thinking to health care: issues and observations. Int J Quality in Health Care. 2009;21(5):341-7.

10. Toussaint J, Gerard RA. On the mend: revolutionizing healthcare to save lives and transform the industry. Cambridge (MA): Lean Enterprise Institute; 2010.

11. Amirahmadi F, Dalbello A, Gronseth D, Mccarthy J. Innovations in the clinical laboratory: an overview of lean principles in the laboratory. USA: Mayo Clinic; 2007. 12. Yin RK. Estudo de caso: Planejamento e Método. 3 ed. São Paulo: Bookman; 2005.

13. Ventura MMO. Estudo de caso como modalidade de pesquisa. Rev SOCERJ. 2007; 20(5):383-6.

14. Minayo MCS. O desafio do conhecimento científico: pesquisa qualitativa em saúde. 2 edição. São Paulo/Rio de Janeiro: Hucitec-Abrasco; 1993.

15. Harari O. Ten reasons why Total Quality Management (TQM) doesn't work. Manage Rev. 1993;82(1):33-8.

16. Eiro NY. Implantação do modelo lean thinking em saúde: um estudo de caso em serviço de medicina diagnóstica [dissertação de mestrado]. São Paulo (SP): Faculdade de Economia, Administração e Contabilidade da Universidade de São Paulo; 2014.

17. Vieira KF, Shitara E, Mendes ME, Sumita NM. A utilidade dos indicadores da qualidade no gerenciamento de laboratórios clínicos. J Bras Patol Med Lab. 2011;47(3):201-10.

18. Coelho SMA, Correa VA, Nunes LENP, Pinto CFD. Integration of value stream map (VSM) and FMEA in the handling and chemotherapeutic infusion process in the clinical oncology service: case study of regional hospital vele do Paraíba. Eng Res. 2012;3(6):1-22. 